\title{
MEDITACIÓN SOBRE EL OFICIO DE CREAR
}

\author{
Silviano Santiago \\ Universidade Federal Fluminense
}

En dos de los últimos volúmenes de ficción que publiqué - O falso mentiroso (2004) e Histórias mal contadas (2005)-intenté dar cuerpo textual a cuatro problemas constitutivos de lo que ha sido para mí el ejercicio de la literatura del yo-los problemas de la experiencia, la memoria, la sinceridad y la verdad poética. Si acepté la invitación para hablarles hoy, no fue con la intención de traer al palco al autor y, con ello, ofrecerles una lectura explicativa de aquellos dos y de otros textos autoficcionales míos. Al contrario. Solo al lector compete la tarea de la lectura. Además, no soy un escritor que busque minimizar el trabajo del lector; en general, lo complico. Suscribo dos versos de Nietzsche en Así habló Zaratustra, que dicen: "Yo odio a todos los ociosos que leen. / Quien conoce al lector no hace ya nada por el lector". Al preguntarle si acaso montaba piezas para su público, Antonin Artaud respondía: "Para el público es necesario ante todo que el teatro exista". En nuestras palabras: para el lector es necesario ante todo que la literatura exista.

El principal objetivo de esta charla es presentarles y, en la medida de lo posible, discutir algunas cuestiones abstractas que han preocupado y preocupan al escritor como personalidad que reflexiona sobre el estatuto de eso que hoy se llama -y él mismo comenzó a llamar- autoficción. Si pidiese ayuda a João Cabral de Melo Neto, estas palabras tendrían por título e intención "Meditación sobre el oficio de crear". A él pido de nuevo ayuda para agregar que la meditación "no tiene nada de predicación ni de sugerencia de recetas posibles".

En mi caso, llegué a la autoficción a través de un largo proceso de diferenciación, preferencia y contaminación. Paso primero a la diferenciación y la preferencia. Partí de la distinción entre discurso autobiográfico y discurso confesional. Los datos autobiográficos atraviesan todos mis escritos y, sin duda, los movilizan, echando por tierra la expresión meramente confesional. Los datos autobiográficos sirven de base a la hora de concebir y componer mis escritos y, eventualmente, pueden servir al lector para explicarlos. Traducen

Este texto fue leído como ponencia en 2008 en el SESC, Río de Janeiro, a pedido de Luciana Hidalgo. Fue recogido posteriormente en el número 18 de la revista Aletria. La traducción es de Eduardo Vergara Torres 
el contacto reflexivo de la subjetividad creadora con los hechos de la realidad, que me condicionan, y los de la existencia, que me conforman. Desde la perspectiva de la forma y del contenido, el discurso autobiográfico per se -en su pureza- es tan proteiforme como un camaleón y tan fluido como el mercurio, aunque cargue con un inmenso legado en la literatura brasileña y occidental.

El discurso propiamente confesional está ausente en mis escritos. En ellos no está en juego la expresión abierta y profunda de sentimientos y emociones secretas, personales e íntimas, entendidas como las únicas verdaderas por tantos escritores de carácter romántico o neorromántico. No nos engañemos, la distinción entre ambos discursos tiene el propósito de subrayar mi familiaridad creativa con lo autobiográfico y el consecuente repliegue de lo confesional al grado cero de la escritura. A pesar de su insoslayable legado para las culturas nacionales, el discurso autobiográfico jamás aparece per se en mis escritos, es decir, no me apropié de él en su pureza subjetiva y sentimental. No escribí mi autobiografía. Una pregunta se impone: entonces, ¿cómo me he valido del discurso autobiográfico en mis escritos? Para responderla, pasemos al tercer movimiento, el de la contaminación.

Al reconocer y adoptar el discurso autobiográfico como fuerza motora de la creación, lo llevé a dejarse contaminar por el conocimiento directo -atento, concentrado e imaginativo- del discurso ficcional de la tradición occidental, de Miguel de Cervantes a James Joyce, por citar sus extremos. No fue por casualidad que, en la juventud, el crítico de cine se matriculó en la Facultad de Letras y se volvió, en su madurez, profesor de literatura. Si mi vida es la que me toca vivir, mi formación fue y está marcada por la lectura de los narradores canónicos y contemporáneos -independiente de su nacionalidad. Con exclusión de la materia que constituye lo meramente confesional, el texto híbrido, constituido por la contaminación de la autobiografía por la ficción -y de la ficción por la autobiografía-, marca la inserción de mi material subjetivo en la tradición literaria occidental, y la relativización por ésta de su anárquico potencial creativo.

Injertar alguna cosa (el discurso autobiográfico) en otra distinta (el discurso ficcional) significa relativizar el poder y los límites de ambas, y significa también abrir nuevas perspectivas de trabajo para el escritor y ofrecerle otras facetas de percepción del objeto literario, ahora diferenciado e híbrido. Ya no valen las respectivas purezas centralizadoras de la autobiografía y de la ficción; son los procesos de hibridación de lo autobiográfico por lo ficcional, y viceversa, los que cuentan. O mejor, son los márgenes, en constante contaminación, los que se ofrecen como lugar de trabajo del escritor y de resolución de los problemas de la escritura creativa.

La fuerza creadora del yo -lo que Michel Foucault llama la resemantización del sujeto por el sujeto- tropieza con la tradición literaria occidental. Tropieza con ella, trastabilla, se levanta, se sacude el polvo y vuelve a avanzar, afirmándose como productora ante el choque con el poder aplastante de la tradición ficcional. De ese modo es que la resemantización del sujeto por el sujeto cobra sustento para cuestionar, por medio de la producción textual, el estatuto contemporáneo tanto de la técnica/artesanía de la ficción (the craft of fiction, en inglés) como del canon ficcional. Con el correr de los años, el vaivén del doble cuestionamiento abrió para mí una brecha de intervención dramática y textual, donde he elaborado las principales características -experiencia, memoria, sinceridad y verdad poética- de la moderna literatura del yo. 
A fin de evitar malentendidos, sostengo que en ningún momento del pasado remoto usé la categoría autoficción para clasificar los textos hibridos que escribí y publiqué. Cuando pude, evité la palabra novela. En el caso de Em liberdade (1981), un diario íntimo falso "de" Graciliano Ramos, clasifiqué el libro como "una ficción de", para desagrado de los editores, que prefieren los lugares comunes. La profesora Ana Maria Bulhões de Carvalho lo clasificó como alterbiografía, un neologismo que destaca el carácter híbrido de la propuesta. No tuve problema en utilizar "memorias" para O falso mentiroso. Memorias tiene una buena tradición ficcional entre nosotros ${ }^{1}$. Finalmente, agrego que me sorprendió alegremente encontrarme con el dato de que Serge Doubrovsky, crítico francés radicado en los Estados Unidos, acuñó, en 1977, el neologismo autoficción y que, en 2004, Vincent Colonna, un joven crítico e historiador de la literatura, se valió del neologismo para escribir el ya indispensable Autofiction \& autres mythomanies littéraires (Paris, Tristram). En suma, comencé a apropiarme de la categoría, posterior y ajena, de autoficción.

Mi trayectoria ciertamente difiere de las de Serge Doubrovsky y Vincent Colonna, y es por eso que acepté la invitación que me hiciera Luciana Hidalgo para participar de este encuentro. Además, Colonna es bastante generoso en su configuración del género híbrido -la autoficción, que motivó su estudio-, optando por clasificar el conjunto de narrativas afines como "una nebulosa de prácticas emparentadas". Escribe que es inmensa la lista de escritores que vienen conformando su identidad por medio de un montaje textual, y agrega: "Desiguales en su riqueza, sus obras son también diferentes en la forma y la amplitud de los procesos de hibridación, pero todas ellas marcan una época, un momento de la historia literaria, en que la ficción del yo [la fiction de soi] ocupa a los más diversos autores, para constituir no tanto un género, sino tal vez una nebulosa de prácticas emparentadas".

Como la autoficción no es una forma simple ni un género adecuadamente codificado por la crítica más reciente, me propongo relatarles mi camino personal. Vuelvo a la distinción inicial entre discurso autobiográfico y confesional.

No esbocé intencionalmente la distinción y mucho menos la elaboré en virtud del intelecto o de la razón. Tampoco la construí de manera fría y pragmática como lugar original de mi práctica literaria. La distinción entre lo autobiográfico y lo confesional tomó cuerpo textual en el momento en que comencé a conjugar mi propia experiencia infantil de vida con ayuda de los recursos de mi memoria. Es decir, desde la más tierna infancia, la distinción entre autobiografía y confesión se conformó y existió en mí y, desde siempre, existe como una fuerza para gatillar la imaginación creadora.

Mi preferencia por el discurso autobiográfico y su consecuente contaminación por el discurso ficcional se tornó práctica textual, es decir, ellas configuran un producto híbrido, en el momento en que el niño/sujeto tuvo la imperiosa necesidad de eludir -o reprimir hacia lo inconsciente- lo confesional y ligar su experiencia de vida a la invención ficcional.

1 Memórias de um sargento de milicias, Memórias póstumas de Brás Cubas y Memórias sentimentais de João Miramar. 
La contaminación se volvió una práctica propiamente literaria en el momento en que el adolescente/sujeto - un esmerado estudiante de Letras- revisitaba las prácticas textuales híbridas de la infancia para hacerlas de dominio público. Al revisitarlas por el ejercicio de la memoria, intenta aprehenderlas con el fin de conjugar el deseo de crear narrativas literarias significativas en el universo cultural brasileño. ¿Mucha pretensión? Tal vez sí, tal vez no. Pero ningún escritor se realiza sin una "ambición justa", para retomar la expresión de Autran Dourado.

Por lo tanto, la preferencia por los datos autobiográficos y la contaminación del discurso autobiográfico por el ficcional existieron desde siempre allá en la infancia y estarán siempre en mis escritos. No saqué la distinción, la preferencia y la contaminación de la nada, no las inventé recientemente y por eso vale la pena revisitar al niño que fui.

Desde niño, por razones de carácter extremadamente personal e íntimo -me refiero a la muerte prematura de mi madre-, no conseguía articular el discurso de la subjetividad plena, o sea, el discurso confesional. En eso tal vez se me ofrecen como paradigmas la infancia de Gustave Flaubert y, principalmente, la madurez de Fernando Pessoa. No estoy queriendo decir que mi personalidad infantil, esto es, mis impulsos vitales y secretos, me fueran desconocidos. Al contrario, los conocía muy bien. Tan bien los conocía que comprendía su alto poder de destrucción y autodestrucción.

Creí tener que ocultar a oídos ajenos la personalidad del niño-suicida y del niñodestructor, esconderla bajo discursos inventados (ficcionales, si me permiten), donde creaba subjetividades similares a la mía, representadas con cierta inocencia y, principalmente, sin culpa en el trato con los hombres. Creaba discursos autobiográficos que no eran confesionales, aunque partiesen del lente multifacético que es el trágico accidente de la pérdida materna. Eran ya discursos ficcionales y, como tales, coexistían amontonados. Ninguno de estos discursos era plena y sinceramente confesional, aunque tomasen el poder de fabulación de la autobiografía. El dato confesional que podía llegar a su condición plena era encubierto, camuflado, para usar el lenguaje de la Segunda Guerra, entonces dominante. No tenía interés en exhibirlo. Los hechos autobiográficos fabulan, aunque nunca quieran adoptar la forma del discurso confesional, ya que se dejaban apropiar por el discurso que vine a conocer en el futuro como ficcional. El sujeto resemantizaba al sujeto por medio del discurso híbrido.

No estoy queriendo decir que no vivía la angustia de no poder articular en público la subjetividad plena, confesional. La vivía, solo que no la ejercitaba como discurso ni la escribía. Aferrarme y sustraerme a esa angustia era el modo vital de la supervivencia del cuerpo y de los impulsos vitales, era el modo como el discurso autobiográfico se distanciaba del discurso confesional y ya flirteaba, inconscientemente, con el discurso ficcional. Donde más fuerte se hacía el sentido de la angustia y más necesaria su sustracción era en el comedor o en el confesionario. Quedémonos con este ejemplo.

Mi padre no era católico practicante, pero nos obligaba a serlo. Seguí el catecismo e hice la primera comunión. Iba a misa todos los domingos. Los sábados, ante el padre confesor de acento germánico (respecto a las connotaciones, véase el periodo histórico), en la penumbra y protegido por el pseudo-anonimato (vivía en una ciudad del interior), tenía que hacer un examen de autoconciencia y ser sincero al enumerar y confesar los 
pecados de la semana. Acostumbraba traerlos escritos en una hoja de papel. Con una pizca de paranoia, y agrego que los pecados eran muchos y, perdón por el juego de palabras, inconfesables. A pesar de la lista que llevaba, no profería en el confesionario un discurso sincero, confesional. Mentía. Ficcionalizaba el sujeto -a mí mismo-al narrar los pecados que constaban en la lista. Inventaba para mí y para el confesor otra(s) infancia(s) menos pecaminosa(s) y más sensata(s), o al menos donde las actitudes e intenciones reprochables permanecían camufladas en el habla.

Esas mentiras, o invenciones autobiográficas, o autoficciones, tenían el estatuto de lo vivido, tenían la consistencia de la experiencia, y eso gracias al acontecimiento que les antecedía -la muerte prematura de la madre- y garantizaba su veracidad o autenticidad. Los sábados, ante el confesor, asumía un habla híbrida -autobiográfica y ficcionalverosímil. Era "confesional" y "sincero" sin, en realidad, serlo plenamente. El niño en el confesionario era ya un falso mentiroso. Hago mías las contundentes palabras de Michel Foucault en La arqueología del saber: "No me pregunten quién soy, ni me pidan que permanezca invariable: es una moral de estado civil la que rige nuestra documentación. Que nos deje en paz cuando se trata de escribir".

En la infancia ya era multiplicadoramente confesional y sincero, era autoficcionalmente confesional y sincero. El discurso confesional -que nunca existió en el dominio públicose articulaba y se articuló desde siempre por la multiplicación explosiva de los discursos autobiográficos que hacían pacto con lo ficcional. El discurso confesional - que en verdad no existía, era apenas un lugar vacío, desesperante, saturado de discursos híbridos-solo podría estar plena y virtualmente en un haz discursivo, en una suma abierta de discursos autoficcionales, cuyo peso y valor final serían responsabilidad del padre confesor -y, hoy, de mi lector. Al padre confesor y al lector deslizaba algunas historias mal contadas.

La buena literatura es una verdad bien contada... por el lector... que se da la tarea de descifrar una historia mal contada por el narrador. Concernía a los oídos del padre confesor -y compete hoy a los ojos del lector- llenar los espacios en blanco y los vacíos de los que también está hecho un texto literario, aunque, no lo dudemos, cualquier texto, que lo diga el psicoanalista. Concierne al lector encumbrar (como una cometa) y enderezar (como algo sinuoso) un objeto de palabras que le es dado de manera convencional y aparentemente en desorden. ¿Un ejemplo? Dom Casmurro es una historia mal contada por el narrador Bentinho sobre el adulterio de su esposa, Capitú, con Ezequiel, el mejor amigo de la pareja. Narrada desde la perspectiva del lector, la historia en primera persona sobre el adulterio de Capitú se transforma en una historia bien contada sobre los celos del personaje Bentinho.

Las historias - todas ellas, diría yo, en un acceso de generalización- están mal contadas porque el narrador, independiente de su deseo consciente de expresarse dentro de los parámetros de la verdad, acaba por sorprenderse por el modo traicionero en que cuenta su historia (al traicionarse, traiciona la letra de la historia que debería estar contando). La verdad no es explícita en una narrativa ficcional, está siempre implícita, recubierta con una capa de mentira, de ficción. No obstante, es la mentira, o la ficción la que narra poéticamente la verdad al lector. 
304

Revista Chilena de Literatura No 88, 2014

Uno de los grandes temas que dramatizo en mis escritos, con el gusto y el placer de la obsesión, es el de la verdad poética. O sea, el tema de la verdad en la ficción, de la experiencia vital humana metamorfoseada por la mentira que es la ficción. Se trata de una paradoja obvia, cuya raíz se remonta a los antiguos griegos. Recientemente encontré una forma moderna de esa paradoja en un dibujo de Jean Cocteau, de la serie griega. Está fechado en noviembre de 1936. En el dibujo vemos un perfil claramente griego, el del poeta y músico Orfeo. De su boca, como en una historieta, sale un globo donde está escrito: "Je suis un mensonge qui dit toujours la vérité" (soy una mentira que dice siempre la verdad). Ese juego entre el narrador de la ficción que es mentiroso y se dice portador de la palabra de la verdad poética, ese juego entre la autobiografía y la invención ficcional, es el que hizo posible que pudiese llevar hasta las últimas consecuencias la verdad en el discurso híbrido. Por una parte, la preocupación claramente autobiográfica (relatar mi propia vida, sentimientos, emociones, modo de enfrentar las cosas y las personas, etc.); por otra, adecuarla a la tradición canónica de la ficción occidental.

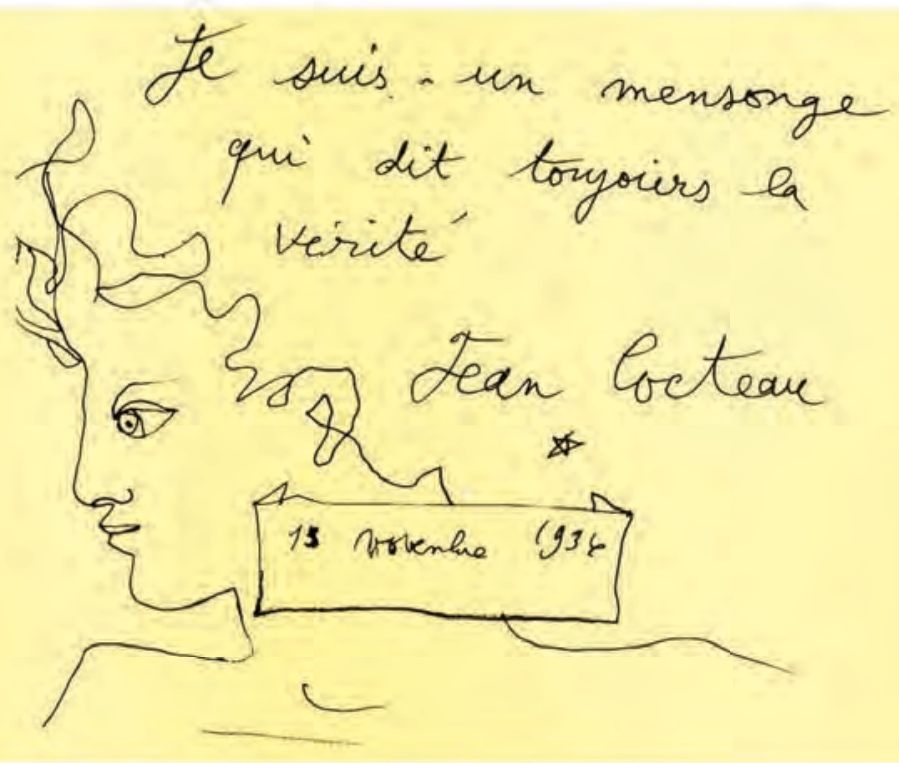

Toda narrativa ficcional en que la verdad poética es transparente -aquello que se llama novela de tesis- es un hastío. La verdad ficcional es algo palpitante, pulsante, que requiere de sismógrafos, estetoscopios y todos los muchos aparejos científicos o quirúrgicos que llevan al lector a detectar todo lo que vibra, pulsa y palpita en el cuadro de la aparente tranquilidad de la narrativa literaria, o sea, en lo mal contado por el lenguaje. En ese sentido, y exclusivamente en ese sentido, lo bien contado es una forma superficial de toda gran narrativa ficcional que es, por definición y profundamente, mal contada. 
Para terminar, leo parte de un fragmento de "Sem aviso", texto firmado por Clarice Lispector: "Comencé a mentir por precaución, y nadie me avisó del peligro de ser precavida, y nunca más la mentira se despegó de mí. Y tanto mentí que comencé a mentir hasta a mi propia mentira. Y eso -aturdida lo sentía- era decir la verdad. Hasta que caí tanto que la mentira la decía cruda, simple, concisa: decía la verdad en bruto". Permítanme una glosa. El sujeto en primera persona comenzó a mentir por prudencia y cautela y, como la realidad del entorno lo incitaba a ser prudente y cauteloso, continuó mintiendo descaradamente. Y a tal punto miente que la mentira se vuelve el modo más radical de ser escritor, de decir la verdad que le es propia, de decir la verdad poética. 